\title{
Development and Emancipation:
}

\section{The Information Society and Decision Support Systems in Local Authorities in Egypt}

\begin{abstract}
Purpose

To investigate the emancipatory promises and realities of ICT in Egypt.

\section{Design/methodology/approach}

The combination of Habermasian and Foucauldian ideas implemented by a critical discourse analysis of the Egyptian Information Society policy and interviews with employees of local decision support systems employees. Promises and rhetoric are contrasted with findings and questioned with regards to their validity.

\section{Findings}

On the policy level, analysis shows that the emancipating rhetoric of ICT is not followed through. ICT is mostly seen as a means of attracting foreign direct investment. Neither political participation nor educational benefits are promoted seriously. On the local level, culture and organisational realities prevent individuals from exploiting the emancipatory potential of the technology.

\section{Originality/value}

The combination of the Habermasian and Foucauldian approach exposes the problems of ICT use in developing countries. It shows that emancipation is used to legitimise ICT policies but is not taken seriously on a policy level in Egypt. Local implementations also 
fail to deliver on their promise. In order to have emancipatory effects, ICT policy and use will need to be reconsidered. 


\section{INTRODUCTION}

Governments and international agencies spend huge amounts of money on projects aimed at promoting the use of information and communication technology (ICT) in so-called developing countries (Mejias, Palmer \& Harvey 1999; Montealegre, 1998). The immediate aim of such investment is typically economic growth (Klenow \& Rodríguez -Clare, 1997; Temple, 1998). It is usually recognised, however, that economic growth is no end in itself. Economic growth is meant to produce employment, create welfare, and improve the lot of all members of society. Its purpose is to allow people to live a fulfilled life according to their own design. Briefly, the final aim of the promotion of ICT in developing countries is the emancipation of the members of society.

This paper sheds doubt on the emancipating effect of ICT. It does so by examining two major applications, namely the information society policy and the use of decision support systems on the local level in Egypt. In order to determine whether empowerment is indeed the aim of ICT use, we look at the accompanying rhetoric and assumptions. These are contrasted with social reality on the national level of the information society policy and on the local level of the organisational use of DSS. We present evidence on the macro and on the micro level that ICT does not have the promised emancipatory effects. Instead, ICT is often actively disempowering. This discrepancy of message and reality is no coincidence. We argue that the disempowering faculties of ICT lie at the heart of the design, plan, and use of the technology.

In order to support these theses we have based this piece of critical research on the theories of two dominant critical theorists, Jürgen Habermas and Michel Foucault. After briefly introducing their respective theoretical standpoints we will develop our methodologies 
based on their ideas. We will use a Habermasian framework to undertake a critical discourse analysis on the macro level of the Egyptian Information Society Policy. This will be complemented by a Foucault-inspired investigation of the organisational practice of using DSS in local authorities. We will use these approaches to focus on two important areas of possible emancipation: democratic participation and education. The result of our empirical findings will be that in both areas ICT has disempowering effects which are known to the agents involved and arguably intended from the outset. The paper will end with a reflection of the findings and the methods and approaches employed.

\section{CRITICAL RESEARCH}

Critical research is an established research approach, sometimes described as an alternative to positivist and interpretive research (Chua, 1986; Orlikowski \& Baroudi, 1991). We suggest a definition of critical research according to critical intention to change social reality and promote emancipation.

\subsection{Critical Intention: Emancipation}

The term "critical research" usually stands for research that is grounded on the assumption that society can and should be improved (Jermier \& Forbes, 2003). At the basis of this assumption one can find Marx's view of history as a series of class struggles (Marx, 1969) and a corresponding conflictual view of society (Hirschheim \& Klein, 1989).

Critical researchers do not simply accept the status quo as the best possible world; they want to know what is "wrong with the world rather than what is right" (Walsham, 2005, 112). They aim to open up discursive closure, to facilitate new descriptions and to initiate 
new discourses (Alvesson \& Deetz, 2000). Critical research wants to challenge accepted realities and promote resistance. It cannot be comfortable; it disturbs the quiet and challenges established authorities.

The way social reality is to be changed by critical research is to promote emancipation (Alvesson \& Willmott, 1992; Hirschheim \& Klein, 1994; Ngwenyama \& Lee, 1997; Ulrich, 2001; Cecez-Kecmanovic, et al, 2002; Varey, et al, 2002; McAulay, et al, 2002). The idea of emancipation is to "help eliminate the causes of unwarranted alienation and domination and thereby enhance the opportunities for realizing human potential" (Klein \& Myers, 1999 p. 69). Emancipatory concerns are frequently linked to concepts that appear to hinder emancipation such as alienation (Orlikowski \& Baroudi, 1991), authenticity (Probert, 2002), identity (Forester, 1992) or a limited rationality (Levy, et al, 2003; Burrell \& Dale, 2003; Saravanamuthu, 2002; Varey, et al, 2002, Ciborra 2000).

Emancipation raises conceptual and practical problems that exceed the limits of this paper (Stahl, 2006). Despite these problems, it has intuitive appeal and is the focal point of critical research. Emancipation also contains ethical connotations and implications, which renders critical research inherently ethical (Stahl, 2008a/b).

\subsection{Consequences of the Critical Intention}

The critical intention has consequences for research in terms of the choice of research topics, theories, and methodologies. Critical research concentrates on those topics that promise a chance of redeeming the critical intention. The typical topics of critical research are thus power, empowerment, and emancipation (Brooke, 2002a; Howcroft \& Trauth, 2004). Power is usually perceived as a pervasive influence on human action, rather than straightforward projection of political or military potency (Mingers, 1992). Critical 
researchers are interested in how power is created and legitimised (Mansell, et al, 1999). The aim of studying power is to identify those who are dominated and to help them

represent their claims better, to empower themselves (Lyytinen \& Hirschheim, 1988; Cecez-Kecmanovic, 2001a; Dawson \& Newman, 2002). Critical researchers in IS have investigated matters of power and empowerment in systems failure (Wilson \& Howcraft, 2002), the digital divide (Kvasny \& Trauth, 2002) or gender issues in IS (Kvasny, et al, 2005).

The intention to emancipate is linked to certain theories which are sensitive to issues of emancipation and alienation, which will be discussed in the next section. There is no clear link between the emancipatory agenda and any particular research methodology (McGrath, 2005), but critical scholars often prefer those approaches which allow them to gain a direct and in-depth contact with respondents, which may contribute to allowing respondents to defining their own way to emancipation.

\section{CRITICAL THEORY: THE DISCOURSE OF FOUCAULT VERSUS} HABERMAS

In this paper we draw on two important bodies of critical theory, namely the work of Michel Foucault and Jürgen Habermas. We will combine both approaches to develop a methodology that allows us to overcome their respective weaknesses.

\subsection{Foucault's Discourse}

"Discourse" is the central concept that combines Foucault's and Habermas's different interests. Foucault explores the conditions of discourses and particularly the criteria of 
inclusion or exclusion of discourses (Foucault, 1971). There are numerous mechanisms that control discourses. Among these one can find sanity / madness, discipline, power, truth, or sexuality. These are important because discourses shape reality including individual identity.

A concept closely linked to discourse is "power". For Foucault, power is not only the ability to dominate others but a relationship of influence between different agents. Power is directly related to knowledge: power defines what counts as legitimate knowledge. Knowledge invests agents with power. Discourses produce power / knowledge but they can also destroy it (Foucault, 1976). The relationship between discourses and power is ambiguous and not predictable (Knights \& Willmott, 1999). Power is created and perpetuated through discipline. Foucault's possibly most widely-read book, "Discipline and Punish" (1975) discusses how discipline of the docile body is used to create discourses and social institutions.

There are numerous examples of Foucauldian approaches in research on ICT or IS (Coombs, et al, 1992; Willcox, 2004). These cover certain technologies such as email (Edenius, 2003) or groups of applications as in e-government (Wastell, 2003). Foucauldian analyses have also been applied to specific cases and problem areas such as exclusion and the digital divide, aspects of IS management such as change management, surveillance or, indeed, the very construction of the discipline of information systems (Introna, 2003). Foucault's theories can be applied in IS research but they also have weaknesses. One of these is his overly wide concept of power. Power pervades all of Foucault's writings to the point that Habermas (1994 p. 62) has called it a "transcendental-historicist" concept. Foucault's idea of power is not necessarily commensurable with our everyday understanding of the term. His wide concept of power renders it impossible to distinguish between desirable and problematic uses of power, which leaves him open to the charge of 
relativism. It is thus hard for Foucault to offer a positive vision or a desirable state of affairs, which, in turn, makes it very difficult to actually strive for and achieve social change. Habermas (1994) argues that the concentration on the micro level of power relationships between individuals has blocked the view of the macro level problems of power, which may be the more pressing issue in today's society.

\subsection{Habermas's Discourse}

Where Foucault attempts to demonstrate the irrational background of allegedly rational discourses, Habermas tries to save rationality from being discarded (Cooper \& Burrell, 1988; Burrell, 1994). Rationality for Habermas is a disposition to give reasons for one's actions. This can best be understood in the framework of his Theory of Communicative Action (TCA) (Habermas 1984a/b). Humans are intrinsically social beings who require social interaction to survive and thrive. Communication is aimed at facilitating cooperation. Communicative action stands for those pieces of communication where the speakers mutually respect each other as autonomous moral beings. Whenever we communicate, each utterance carries several validity claims: those of truth (Wahrheit), legitimacy (Richtigkeit), and authenticity (Wahrhaftigkeit). A further condition of successful communication, which in the English-language literature is often counted as a fourth validity claim, is that of clarity or comprehensibility (cf. Waring, 2004).

It is part of the nature of communication that we do not always agree on the validity claims of all utterances. If this is the case, then discourses take place. Discourses are acts of communication that aim at clarifying contentious validity claims. Discourses are characterised by the attempt to emulate the so-called "ideal speech situation", where the only criterion that will decide their outcome is the quality of the argument (Habermas, 
1996). The ideal speech situation is never realised in discourses; it is a necessary (transcendental) condition of the possibility of discourses.

The Habermasian framework has been widely received and applied in IS (Klein \& Huynh, 2004). Communicative action requires speakers to accept the fundamental equality of others and is thus intrinsically ethical. In IS research these ideas have been applied in two major directions: a critique of research methods and approaches and the attempt to create more "socially informed" methods and theories (Lyytinen, 1992 p. 164). The latter aspect, the attempt to use Habermasian discourse theory to inform practice, is closely aligned with the critical intention to change current practices and to emancipate users of IS (Hirschheim \& Klein, 1994). This ethical ideal is closely linked to the ideal speech situation, which is taken as an normative ideal used to model reality (Apel, 1988; Ulrich, 2001).

Examples of Habermasian research in IS range from fundamental explorations of the impact of ICT on communication (Ess, 1996) to applied considerations of how IS development processes can be improved (Elkjaer et al., 1991; Ulrich, 2001). The areas of application of these thoughts range from e-government / e-democracy (Heng \& de Moor, 2003) to e-teaching / e-learning (Settle \& Berthiaume, 2002) and the definition of the field of information systems (Hirschheim \& Klein, 2003).

The attempt to base research on Habermas's theories can also produce problems. There is the egalitarian assumption that all stakeholders should be equal and the resulting bias toward participatory approaches, which often runs counter to capitalist hierarchies (Howcroft \& Wilson, 2003). There are the intricacies of language and the problem of meaning, which a Habermasian researcher must take seriously (Cecez-Kecmanovic, 2001b). Furthermore, there are also fundamental and conceptual problems with the application of Habermas's theories in organisational practice. Chief among them is the 
dichotomy of ideal and real discourses and the resulting question of the theoretical status of real discourses.

\subsection{The Combination of a Foucauldian and Habermasian Approach}

There has been some debate concerning the relationship of Habermas's and Foucault's theories (cf. Ashenden \& Owen, 1999; Kelly, 1994). To some degree they can be seen as contradictory with Habermas focusing on transcendental conditions of discourse whereas Foucault concentrates on the genealogy of real discourses. We believe, however, that both can be read as expressions of the critical intention to promote emancipation. Habermas can sharpen our awareness of how discourses should be structured in order to be emancipatory. Foucault, on the other hand, points out alienating influences on extant discourses (Steffy \& Grimes, 1992). In this paper we aim to show that a combination of the two approaches is possible and that it contributes to the critical attempt to improve the status quo by promoting emancipation. This leads to the methodological question of how such an approach can be put into practice.

\section{CRITICAL METHODOLOGY}

Neither Foucault nor Habermas are particularly clear on how their theories can be used in practical research (cf. McGrath, 2005). Part of the reason for this is the nature of critical research, which, by definition, cannot consist of the "application" of a theory to a given situation. Current critical methodologies are often similar to interpretive ones in using predominantly qualitative approaches such as semi- or unstructured interviews, ethnography, action research, and case studies. The difference to interpretive research is 
that empirical "data" is used for the purpose of changing reality and not only describing it. Furthermore, the importance of "data" is diminished because data (literally "things given") is never given but always constructed with a purpose. The very idea of gathering evidence is already part of a Foucauldian regime of truth that cannot claim to be privileged over other sources of texts (cf. Doolin, 1998).

Critical research requires a high level of reflexivity of the researcher, which includes a critical distance to research methods. Whatever method is used, it should help the researcher gain distance from the research object and facilitate non-conventional understanding (Alvesson \& Deetz, 2000).

\subsection{Critique of the Use of ICT in Egypt}

The starting point of this research was the apparent empowering properties of the use of ICT in the "developing" world. When choosing our methodological approaches we thus considered which aspects of these claims would be open to critical scrutiny and how we could conduct such critical analyses. One characteristic of the use of ICT for developmental purposes is that it tends to be highly centralised. It is often driven by external agencies and organised by national governments. We therefore believed that it would be essential to extend the scope of the study to explicitly include the national political level. At the same time we wanted to explore whether ICT use has an empowering effect on the individual and organisational level. We also assumed that there would be a relationship between a political view of empowerment and organisational practice. The challenge was thus to find a research approach that allowed us to study the level of national politics and organisational reality. Furthermore we needed a methodology that would allow us to question the status quo we found and to open discursive closures. We addressed these 
challenges by applying a Habermasian view on the macro level of national politics and following up the issues found there by a Foucauldian analysis on the micro level. These two approaches, which will be discussed in more detail below, were used to identify claims to empowerment and contrast these with social reality.

\subsection{Habermasian Analysis: Critical Discourse Analysis on the Macro-Level}

In order to identify contradictions between rhetoric and reality in the Egyptian ICT policy, we decided to do a critical discourse analysis (CDA) (cf. Fairclough, 1993; Chouliaraki \& Fairclough, 1999; Schultze \& Leidner, 2002; Fairclough, 2003) using a Habermasian framework. We decided to follow Cukier et al.'s $(2003,2004)$ method. This method is based on Habermas's four validity claims (Lyytinen, 1992). It aims to identify these claims, using quantitative and qualitative measures, and thereby explicate the hidden assumptions of texts and discourses. Validity claims are discovered and coded by using a guiding question for each of the four claims: truth, legitimacy, sincerity, and clarity. To help us identify claims, we followed the guiding questions put forward by Cukier et al. Drawing on these questions, texts were coded and validity claims in each text were determined. During the coding several individual claims were noted as frequent and worthy of their own category or sub-category. The main advantage of this approach to critical discourse analysis over traditional methods is that it allows the analysis of a larger body of texts.

The method was applied to the Egyptian Information Society policy. The policy documents can be accessed from the Ministry of Communication and Information Technology's (MCIT) homepage (http://www.mcit.gov.eg/index.asp) under the link "E-Bridges". MCIT was chosen because it is the government department responsible for ICT. It is also the trendsetter among the Egyptian ministries and the organisation primarily responsible for 
policy and implementation of ICT in Egypt. The ICT policy is of high importance in Egypt and is supported by President Mubarak. MCIT was set up in 1999 to realise the National Project for Technology Development (El Sayed \& Westrup, 2003). External business observers view MCIT as a reliable partner and a forerunner of reform in the Egyptian administration (anonymous, 2004a).

The policy is presented on 43 web pages with a length varying from $1 / 2$ to 10 pages when printed out. It gives an overview of the intended use of ICT in Egypt and its contribution to the information society in general. The seven most important policy areas, including ebusiness and e-government, are outlined in five web pages each, which discuss the intention, principles, implementation, current state, and planned action for each.

\subsection{Foucauldian Analysis: Power, Surveillance, and Self-Surveillance on the Micro- Level}

Corresponding to the Habermasian methodology on the macro level, we used a Foucauldian view on the organisational level. Foucault's theories lend themselves to a micro-level analysis because he was interested in the individual rather than greater social structures. Change and resistance are anchored on the local level (Chan, 2000). Power is exercised within the social body, rather than from above. It structures possible fields of action (Doolin, 2004). Specific aspects that allow analysing micro-level power from the Foucauldian angle are bodily discipline, surveillance, and self-surveillance. Our questions thus were: are there aspects of bodily behaviour that are linked to ICT use and that indicate power relationships? Are people observed by ICT, do they use ICT to observe others? And do they observe themselves with regards to the systems in such a way that power relationships become clear (Deetz, 1992; Doolin, 2004)? A related useful aspect of 
Foucault's writings is the idea of a regime of truth. Regimes of truth are the social constellations that allow the designation of true statements. They are affected by the mechanisms that allow the distinction between true and false, the means of sanctioning truth, or the states of those who sanction truth (Introna \& Whittaker, 2004)

Since we wanted to use the Foucauldian lens to explore the empowering effect of ICT on the organisational level, we chose an application that is widely spread throughout Egypt and linked to government structures. This application, the decision support units of the local governorates, is probably the most widely-researched one concerning ICT in Egypt (Shoib \& Jones, 2003). It is a public sector project that has been developed across Egypt which has established information and decision support centres in each of the country's 27 governorates. Part of the aim of this project was to diffuse the use of IT to administrators outside of Cairo and Alexandria (Nidumolu et al, 1996). The first Information and Decision Support Centre (IDSC) was established by the cabinet to develop decision support systems for the Cabinet and top policy makers (El Sherif \& El Sawy, 1988).

From 1987 onwards, IDSCs, modelled on the Cabinet IDSC were established in each of the 27 governorates. Each IDSC consists of statistics, computer resource, decision support, library and publication units. The statistics unit collects information at the governorate level by collating information from many district level IDSCs, modelled on the governorate IDSC. This information is collected for sectoral databases looking at population, health and housing. By 1998, there were 1202 district level DSCs employing 7300 staff (Elbeltagi, McBride \& Hardaker, 2005).

In order to establish the organisational reality of empowerment and to view it through a Foucauldian lens, we conducted face-to-face interviews with individuals involved in the DSCs. The majority of our interviewees were either CEOs or managers of the DSC. We conducted the interviews in two stages: one set of 13 interviews was conducted from April 
to June 2000 and aimed to establish a general understanding of the work of the units. The second set of 12 interviews was conducted between June 2004 and March 2005. During this second set of interviews we emphasised the question of emancipation.

\section{THE (DIS)EMPOWERING EFFECTS OF ICT IN EGYPT}

In this section we will present and discuss the findings of our research. We will start by identifying claims to empowerment through the use of ICT. These will then be contrasted by observations of social reality. The aim is to see whether the claims to empowerment are matched by empowering practices. During our research we identified two salient areas where empowering claims and reality came into obvious tension, namely democratic participation and education.

A final caveat is in order at this point: The following narrative will attempt to draw a convincing picture of the lack of empowerment through ICT in Egypt that we encountered during our research. We have therefore decided to concentrate on those aspects that will allow us to develop a linear story that renders our arguments plausible. The price we pay for this is a diminishing of the complexity of the realities that we encountered. We believe to be justified in doing this because all research can be seen as an attempt to reduce complexity and create order out of chaos (Weizenbaum, 1976). As critical researchers we are sceptical about the possibility of giving an "objective" account of reality. So, rather than try and be objective, we prefer to clearly signal our viewpoint for the reader to contextualise it with his or her experiences and perceptions. 


\subsection{Democracy and Participation in the Egyptian ICT Policy}

\subsubsection{Claims to Empowerment}

In one of the central speeches promoting the ICT effort in Egypt, the Egyptian President Hosni Mubarak (1999) said that the purpose of information technology is to facilitate a "better living to all the Egyptians". A similar reference to "enhancing the quality of life for each and every Egyptian" was repeated by the President (Mubarak 2000). Empowerment of the Information Society is the explicit aim of the Information Society Development Office, an organisation charged by MCIT with promoting the information society (ISDO, 2005). All of this suggests that empowerment is indeed a central aim of the use of ICT.

This empowering idea is repeated throughout the policy document. The information society, which is the centre of attention of the ICT policy, is said to be a society where "citizens are empowered [...]" [2] $]^{1}$. Different aspects of the policy empower different stakeholders such as the Egyptian IT community [17]. The empowerment includes participation and explicitly mentions that ICT will allow "genuine participation of citizens, including traditionally marginalized segments of the population" [2]. Two groups discussed specifically are women where ICT training is meant to "close the gender gap" [17] and "enhance the role of women in managing commercial activities" [27] as well as disabled people [13], specifically the visually impaired [47].

This development of participation will lead to "greater opportunities for all" [3]. Part of the process will be increased transparency, for example in the banking industry [27], as well as

\footnotetext{
${ }^{1}$ The references in [angle brackets] refer to the policy website. A complete list of the documents can be found in Stahl (2008a).
} 
national and international solidarity [54]. A particular emphasis is given to freedom, especially the market freedom to do business and be successful, thereby overcoming the problem of poverty. Participation is to be supported by e-government which will "bring the benefits of the emerging global information society to the largest possible segment of the population" [19] and allow for "community participation" [20]. Best of all, the potential of ICT is not something we will have to wait for much longer. "A fully functioning, effective Egyptian Information Society is now just around the corner." [53]

Part of this empowering information society is realised through the local use of the DSC. A project whose central mission is to diffuse the use of IT away from central administrations and give local managers support in making their own decisions through the use of a DSS should be emancipatory and empowering. The DSS should be a tool for gathering local information and enabling the users to make informed decisions concerning the local distribution of resources.

\subsubsection{Macro Level Critique}

The emancipatory rhetoric of ICT and the information society is contrasted starkly by social realities. Political participation as an expression of empowerment is highly limited. Egypt officially claims to be a democratic system (Egypt 2004) but the implementation of a "presidential republic" where the main power holder is nominated by the People's Assembly and then confirmed by referendum leaves little space for political freedom. Compared to other countries Egypt's political system may be relatively liberal and allow for limited opposition activities (Nidumolu et al., 1996). Egypt also seems set for a further course of political liberalisation with the recent creation of a National Council for Human Rights, the appointment of the first female judge, and the cancellation of state security 
courts (anonymous, 2004b). Also, Egypt has traditionally allowed greater openness and accountability in political decisions than other countries (El Sherif \& El Sawy, 1988). However, Egypt is still ruled under Emergency Law.

While the external political environment does not appear to be conducive to personal emancipation, a closer look at the policy itself shows that the emancipating claims are not taken seriously and not followed through. The general gist of the policy document is one of top-down development of ICT applications most of which are geared for specific stakeholder groups. Of 256 claims which identify a stakeholder, 156 refer to the government itself. The large majority of the remaining stakeholder claims (71) refer to businesses. Citizens are only identified as stakeholders 20 times. And where they are recognised as stakeholders they are invariably seen as passive recipients of government services. In the 16 of the 17 cases where an omission of relevant stakeholders was identified, these missing stakeholders were the citizens. No input from citizens to the development of the information society is sought.

A strong example of this exclusion of citizens from empowering participation is the "egovernment" section of the policy [19]-[23]. The focus of e-government is the efficient provision of services to citizens, and, more importantly, to investors. Citizen input or even e-democratic participative models are not considered. Where decisions have to be made which stakeholders will be served first, business invariably wins the day over citizens [23]. The analysis of the text allows the conclusion that e-government does not involve any influence on political decisions. Also, e-government is very much seen in terms of ecommerce with one of the case studies and success stories of e-government [22] describing an online billing system. The problems of equating citizens and consumers (Stahl, 2005) are generally ignored. 


\subsubsection{Micro Level Critique}

The lack of empowering structure on the macro level is reflected on the organisational level of the DSS. The DSS has become a tool for reinforcing existing power structures through the support of an information flow directed towards the centre, symbolic support of power structures and encouragement to conformity. Staff in the IDSCs were aware of the inconsistency between the way the DSS was being used and the ideal goal of a DSS in the organisation. For example, a manager in the DSS unit of the El Monofia governorate said 'these type of systems will enable managers in the lower level to be on the same level of importance to the senior managers which is not accepted either by the manager in the top level or even the managers in the lower level who is not prepared yet for this.'

One of the managers in the information centre in the governorate of Aswan said: that 'the role of DSS unit in making strategic decisions is very minimal if there is any role at all. The unit's only purpose is for collecting, saving data and sending it to the IDSC in the central government. The data is inaccurate because they are not able to get it from the right source'. He added that generally 'more than $85 \%$ of the decisions are made without taking in considerations of information technology in general and DSS in particular.'

Although there is an understanding of the rationale for implementing a decision support system to enable more objective decisions to be made, particularly concerning resource allocation, on the basis of concrete statistics, this is largely ignored. A manager in the El Monofia governorate said, 'we make strategic decisions at the local level in meetings where the governor takes most of the responsibility and we are there to give our opinion if he asks us.' Governors tend to ignore the DSC and make decisions based on what they think central government will expect, decisions that will reinforce existing hierarchical structures. Data provided by the DSC and the possible decisions which may be inferred 
from the data are explicitly ignored. In the Domyat governorate a DSC unit manager said that he had not seen a strategic decision made on the basis of information he provided in 14 years. For example, where the information collected by the DSS unit suggested that a certain street should be paved, this was ignored. Instead, a different street was paved because the Member of Parliament lived there. We came across a number of similar examples.

At a micro level, the functions and roles of the DSS are established in line with cultural expectations. The culture of Egyptian society and public sector management depends on position and hierarchical power. Bosses are to be obeyed, rules are to be followed, seniority matters and decisions from above should not be questioned regardless of the implementer's view of whether they make sense. In the Elmenia governorate, a manager said 'the local authority has a very military culture to the extent that if you enter the door of the head of the city or one of the managers you need to go through a lot of people and you are not allowed to sit or talk until he gives you permission. If the manager passes by you should leave what you're doing and immediately stand.' Such a culture in the public sector is reinforced by the approved recruitment of senior public sector officers from senior positions in the security forces. 'The reason is that these people will be trained through their career to listen to instructions and not to make decisions' said one Governorate manager. 'The government does not need to control anything more than what they are doing because they make sure only the people who will follow their policy and guidelines are appointed to key positions.' Such obedience to hierarchical power is arguably part of the Egyptian tradition of civil service.

While these observations represent a rather traditional view of power as top down hierarchy, they can be supported from a Foucauldian point of view. The cultural and military aspects can be seen as part of the genealogy of power that explains the stabilisation 
of current power relationships. There is a strong undercurrent of surveillance and selfsurveillance with regards to the use of DSS. The technology is sometimes overtly used to observe data input and thus individual behaviour. More importantly, it has created a culture of pre-emptive obedience, which is based on self-surveillance. This means that users know which data are required and which decisions are desired and they strive to provide the data that will serve the purpose. At the same time, they make sure that they are perceived as fulfilling the expected wishes of their superiors. This act of self-surveillance is usually done sub-consciously but in some cases it became explicit. For example, in one city the DSS manager, who had described the lack of resources for using the DSS, expressed different views once he realised that his boss would also be interviewed. He asked us to only tell the boss the good things and to assure the boss that the system was being used $100 \%$.

Another Foucauldian angle is that of bodily discipline. Such bodily discipline is reflected in some of the above quotes which indicate certain physical behaviour is required to express power relationships, such as standing up in the presence of superiors. The bodily discipline is closely linked to the military background of many of the managers and governors. Indeed, the military is one of Foucault's recurring examples of the creation of bodily discipline. We would argue that the Egyptian DSS (and administration in general) uses bodily discipline as a means of strengthening power structures. It does so by relying on individuals who are socialised to this type of discipline in the military.

As a final Foucauldian angle, one can see the system of national and local DSS as part of the creation of a regime of truth. Any information system encodes a business process or a set of activities. The use of a DSS requires structured data collection. It encodes a set of tasks. These involve collecting specific kinds of data from the social environment and entering them into the system. The DSS will constrain users to a certain structure of data 
collection. That structure is defined by central government who design the system. Some data is given importance, some is excluded. This structure of legitimate problems is enforced by the more or less subtle use of the DSS as a means to ensure compliance. An important aspect of this is that the local DSS provide employment and status for 7500 well educated employees who are thus bound to be compliant and who will serve as multipliers of the established regime of truth, rather than question it.

\subsection{Empowerment through Education}

\subsubsection{Claims to Empowerment}

It has become conventional wisdom that, in order to participate in society and lead a fulfilled life, one needs a certain amount of education. The Egyptian ICT policy reflects this standpoint and uses ICT as a lever for improving the provision of education to its citizens. The e-learning initiative aims to provide equal opportunities for learning "regardless of age, gender, class, or geographical location" [15]. ICT is meant to improve all levels of education. On the most basic level it will "strengthen attempts to eradicate illiteracy" [17] and "encourage people to overcome illiteracy" [18]. At the same time the provision of ICT facilities in schools and universities will improve the quality of learning. It will provide much-needed capacity in higher education and increase the "competitiveness of [Egypt's] graduates" [13]. Teaching technology will also allow continuing education and life-long learning. A specific emphasis is placed on teaching ICT skills as these are seen as important for the job market and for international competitiveness [11]. 
The policy concedes that there are problems, most notably those of access, usage, skills [4], but also the general level of literacy and overcrowding of the educational system. However, the very use of ICT is seen as the solution to these and the correct usage of technology in education will take care of them. In order to persuade students to learn ICT skills, the government has set up a Basic Skills Training Program which is available free of charge to every young Egyptian and is even linked to a stipend [17]. Additionally, the government has initiated several programmes which are aimed at spreading ICT around the country in a manner that will guarantee access to technology for everyone interested [11]. International cooperation, for example with UK universities, will help overcome the shortage problem of higher education [17].

\subsubsection{Macro Level Critique}

The Egyptian education system faces serious problems. The level of illiteracy in the Egyptian population is close to $30 \%$. Literacy is a concept that is hard to define, but literacy as a condition of participation in an information society is a multi-facetted competence that requires intensive educational effort (Mason, 1986). It seems to be an unrealistic assumption that the mere provision of technology will solve the problem of illiteracy. Furthermore the introduction of ICT will produce more need for traditional education rather than alleviate pressure.

The Egyptian educational system is not well equipped to deal with the challenges of the information society. It performs poorly when compared to other developing countries, partly because of its bureaucratic structure and its outdated pedagogical model (Warschauer, 2003). On top of this there is the demographic development with the number of secondary school graduates doubling from 375000 to 650000 from 2003 to 2005 alone 
and a further expected increase to 1200000 by 2017 [13]. Even a perfect system would find it extremely hard to deal with this sort of challenge.

The solution outlined in the government policy, namely to leverage technology to solve the problem, is unlikely to solve it. It is insensitive to contextual, political, and pedagogic issues. It concentrates on technical matters, most notably on the provision of equipment and technical access, which, at best, will be preconditions for a successful use of ICT. In the document on e-readiness entitled "The Way Forward" [12], the government concentrates on technicalities of access provision that are so advanced that they would have little relevance even in the most developed societies. The concentration on technology allows sidestepping the more difficult social issues behind the education problem (Warschauer, 2003). Solutions are suggested, such as the use of schools as publicly accessible Internet cafes [15], [17] which go counter to the established use of ICT. Finally, the literature on eteaching and e-learning, which suggests that the introduction of technology into education may introduce new problems (Stahl, 2004), is ignored.

ICT education, which is praised as a solution, is in practice organised so that it is impossible for students to fail. Due to the lack of equipment, ICT education is often done theoretically without access to technology. And even where technology is available, it is often not made accessible to students because it is perceived as being too valuable (Warschauer, 2003). The policy itself demonstrates that the government is not following through on its emancipatory promises. If education is to lead to emancipation, then one would expect that teachers and students as main stakeholders would have a say in its provision. However, rather than seeing students as active participants of education, they are passive recipients. Where stakeholders of education are explicitly named, we find the names of major corporations [17]. Education is not seen as an end in itself or as a means of empowerment but rather as a way to produce "human capital" and make Egypt attractive to 
foreign investment. Literacy or education are named relatively frequently as benefits of ICT (37 times) but this number pales in comparison to economic benefits, which are cited 110 times.

In general, the use of ICT is promoted as a way of solving the very serious problem Egypt is facing with regard to educating its rapidly growing population. However, the discourse concentrates on technical matters, thus leaving unexplored the more important underlying questions such as the purpose of education (cf. Sahay, 2004), the pedagogical fit of technology, and the greater social issues such as illiteracy.

\subsubsection{Micro Level Critique}

Education is a central area where Foucauldian ideas of the generation and perpetuation of power structures gain importance (Foucault, 1975). Regarding the local DSS, the immediate impression we got was that of a lack of education and training on the side of the employees and users. In the DSS unit of the El Qalubiya Governorate one employee sat quietly at his desk watching a film on the PC, another played solitaire. They turned to see the arrival of the researcher. 'I've come to do an interview with one of the managers' 'Do you know about DSS?' an employee asked. 'Can you give us information to help us use the system properly?' At the Dakhlia Governorate, the researcher was warmly welcomed as a source of wisdom about DSSs. Far from increasing computer literacy and encouraging learning, the DSS in the local governorates tends to act as a block to learning, another black box to which the privileged have some access.

Hence the implementation of the DSS may be interpreted as a disempowering act because it establishes a new symbol of exclusion. Those who are not trained may look on it as a barrier to their empowerment, while those trained may see it as a privilege which increases 
their submissiveness and obedience within the social structures and encourages selfsurveillance.

That is not to say training wasn't available. But training in computer skills and problem analyses was centralised in Cairo (Nidumolu et al, 1996) Travel for such training was difficult and involved staying away in Cairo which caused difficult problems for employees with supplementary jobs and family responsibilities.

The excuse for centralisation in Cairo was a lack of trainers and equipment. However, since equipment was available locally, it could be envisaged that the trainers would tour governorates and local trainers could be appointed. It is more likely that the centralisation of the training enabled centralised control over what employees learnt and how they used the system. However, the perception of DSS as a power artefact for the privileged few also led to a situation where 'some people who even travel to IDSC in Cairo and get this training are not willing to share their experience when they come back, otherwise they will lose a source of power they have if most of the rest of the people know what they know.'

In the Egyptian context, the status of the trainers needs to be considered. If the position of the teacher is one of high power status, through his being able to tell others what to do with an information system and how to do it, then training DSS managers could only be culturally acceptable if done by a very senior manager. One DSS manager in a city in the ElGharbia governorate said, 'if anybody is going to train me in the use of DSS it better be an experienced head of a city council who has used the system.'

The shortcomings of the educational systems and their effect on the use of systems such as the DSS were a recurring theme in the interviews. At the micro level there was a perception that there was a lack of resources in education. One manager in the Aswan governorate said, 'if we are to sort out the problems of using IT in local authorities, we need to start with the root of the problem which is in the education system. We lack teachers and 
resources like PC labs and even up-to-date textbooks not only at a basic level, but also in the universities as well.' This perception of the resource inadequacy of the Egyptian education system is only reinforced by the view of its cultural shortcomings. An education system based on learning facts provided by teachers and excluding critical thinking inhibits the ability to use IT in a creative and critical way. A manager in the Domyat Governorate said, 'The employees graduate mainly from the universities of Egypt. So they have most of the education system's diseases like lack of innovation and poor skills usage.'

Even when Egyptian nationals are trained abroad and pick up more liberal educational values, the impact on Egyptian educational culture is minimal: 'A big problem we have in Egypt on the macro level which has an effect on the micro level here in local authorities, is the brain drain. There are about 750,000 immigrants to Europe from Egypt and those people have masters and PhDs. This costs the central budget billions of dollars investment. We end up with a lack of human resources and even qualified people here lose motivation because of their financial problems.' (DSS Unit Manager, El Sharkia Governorate). People who may have the intellectual capacity and cultural awareness to challenge and change the culture of education often do not return to the Egyptian education system.

Such a prevalent perception, at the micro level, of the inherent inadequacy of education in Egypt, catalyses a sense of helplessness and disempowerment. There seems to be nothing the manager can do when faced with an overwhelming ingrained problem at the macro level.

These observations are again amenable to a Foucauldian interpretation. Foucault emphasises the relationship of power and knowledge, both of which are affected by education. The DSS are objects of power in a traditional sense because they help make political decisions. More importantly, they define valid knowledge and are thus an important constitutive element of a regime of truth. They are part of the network that 
defines power relationships. The bodily aspect pervades through the management culture, which is influenced by the military background of many managers. There is also an aspect of bodily power in the fact that training is only offered in Cairo, which, for most users, requires physical relocation. The dual aspect of education as a precondition of the use of DSS in the governorates and education / training for the specific application thus offers a number of Foucauldian angles which explain how power relationships are created and solidified though the use of ICT.

\subsection{Summary of Findings}

The above description of our research findings supports the conclusion that the use of ICT in Egypt, on the national level of the Information Society Policy, as well as on the organisational level of the local authorities' use of DSCs is actively disempowering. There is a strong emancipating rhetoric on both levels. This can easily be seen in the wording of the policy documents but it is also obvious in the promises of the micro level. This emancipating rhetoric is an important aspect of the promotion of ICT because it lends legitimacy to the endeavour.

This emancipating promise of ICT is not kept. The very different theoretical frameworks of Habermas and Foucault allowed us to identify contradictions between the rhetoric and the underlying intention. Our critical discourse analysis demonstrated that the rhetorical validity claims are contradicted within the policy itself. The general gist of the policy document is one of one-sided economic liberalism that is fundamentally unconcerned with emancipation.

Similarly, on the local level users and managers of the DSCs are aware of the emancipating potential of the technology but they are equally aware that emancipation is not intended. 
The Foucauldian viewpoint allowed us to identify instances of surveillance, selfsurveillance, and active construction of power/knowledge that ran counter to emancipatory ideals. This could consistently be shown in the areas of political participation and education, both of which could play a central role in the realisation of emancipation, were it taken seriously. We thus believe that we have achieved what we indicated in the introduction, namely to provide evidence for the disempowering faculties of ICT in Egypt.

\section{REFLECTIONS}

Critical research claims to be reflective. In order to live up to this standard, it needs to reflect on itself. Weaknesses, biases, alternatives and assumptions must be subject to critical reflection. This goes beyond the usual discussion of limitations and must question the heart of the research.

\subsection{Theory and Methodology}

There are a number of questions one could raise about the use of concepts, theory and methodology in this piece of research. A visible omission of the paper is our lack of a definition of "development". The term is contentious and divisive (Escobar, 1995) and we felt that a prolonged discussion would add little to the paper. Egypt is a developing country by most standards and the use of ICT is linked to efforts of development, however defined. An important part of the critical reflection aims at clarifying the assumptions and biases the research is based on. Our most important bias is that we developed our argument in the western tradition of thought whose applicability to Egypt is not self-evident. This raises the difficult problem of the transferability of thoughts between cultures (cf. Walsham, 2001; 
Stahl \& El Beltagi 2004). Without being able to argue this point conclusively here, we believe that the aim of emancipating and empowering people is universal and can be applied to non-western environments as well as to western ones (Stahl, 2006). We concede that empowerment may take a different form in the Arab world than in the west. In order to accommodate this, we employed a procedural approach which used a concept of empowerment that was put forward by the research subjects.

\subsection{Exclusion of other Stories}

By developing the present narrative we had to choose which aspects to discuss and which to neglect. This story therefore hides a multitude of other possible stories which may also be worth exploring. There are a few obvious candidates for alternative critical narratives of ICT use in Egypt. One of them is the international political order with its important influence on Egyptian politics. Western democracies seem to agree that peace and quiet in the Middle East (again, a western description) is a political aim of high importance and they therefore stabilise the Egyptian government as best as they can. One can easily draw a line from Egyptian politics to the struggle of Israel and the Palestinians but also to other political developments in the Middle East. This, in turn is linked with questions of the desirability of certain types of government over others. There is an important connection to religious matters and the west's attempt to limit the power of political Islam. This, in turn is linked to the worldwide fear of terrorism, which influences western policies.

Another issue is that we have attempted to present our narrative in as linear and unequivocal a fashion as possible in order to make it more accessible to the reader. While we hope that we were successful in doing this, we realise that we may have neglected some important aspects. One of these is the concept of resistance. In the attempt to show that ICT 
is used for disempowerment we did not pay attention to the idea of resistance. Any Foucauldian scholar will know that for Foucault there is no power without resistance (Foucault, 1980). Similarly, there were examples of resistance to the government's approach and the normalising power in the vicinity of local DSS. Space constraints precluded us from exploring these aspects. Critical research is never finished and always needs to be contextualised. We therefore believe that our omission of resistance and other observations counter to our narrative is justified by the fact that this paper is only one contribution to a larger discourse.

\subsection{Success and Future of the Investigation}

This paper does not offer any simple advice or recommendations on how to use ICT in Egypt. We nevertheless believe that our investigation succeeded in realising the critical intention to make a difference because it facilitated one of the main aims of critical research, namely the exposure of reifications and the opening of discursive closures. This paper has exposed the claimed emancipatory ideals of Egyptian top officials including the President as false or, at best, misleading. As a result of our research, further work using the emancipatory rhetoric will lose legitimacy. The paper will thus contribute to a discourse on how ICT can be used to promote emancipation and this discourse itself will be a success. It will be harder for western consultants to promote their agendas without interacting with local participants.

We do not claim to know how an emancipatory use of ICT in Egypt should be achieved. But we believe that the way to find out will require greater participation by everybody involved, including the citizens of the country. Currently the political system and local culture mitigate against such an approach. It is therefore safe to assume that the 
achievement of emancipation will take some time and that it will require considerable social changes. These will not be easy and they will require a realignment of power relationships. They will also most likely go far beyond the question of ICT use and affect large parts of the society and the political establishment.

This leads us to the role that researchers can play in future developments. There are a number of areas where they can become active. On a functional level, one should remember the emancipatory ideals when working on IS in developing countries. Researchers need to develop a greater sensitivity for the emancipatory quality (or lack thereof) of their work. They also need to be more aware of their environment and the interaction between the higher political levels and the organisational and individual use of technology.

Researchers should also consider the larger political and legal framework. The majority of arguments put forward in this paper could easily be used within developed democracies as well. The Egyptian information society policy, for example, is modelled very closely along the lines of western counterparts. We thus believe that similar critical approaches are necessary within the "developed" world as well. It therefore seems necessary to broaden the critical approach developed here to include democratic countries and the interaction between western and developed countries.

ICT and information systems have long held a huge emancipatory potential that so far has not been realised. We believe that critical research can help overcome this problem and thereby change technology to the status it should have: a means of achieving the individual and collective good life. 


\section{REFERENCES:}

Alvesson, M. \& Deetz, S. (2000) Doing Critical Management Research, SAGE, London, Alvesson, M. \& Willmott, H. (1992) "On the Idea of Emancipation in Management and Organization Studies," Academy of Management Review (17:3), pp. 432 - 464

anonymous (2004a) "Two for TE? It's been an exciting year for the telecommunications industry," Annual Business Economic and Political Review: Egypt. available: www.oxfordbusinessgroup.com [accessed 01.11.2004], pp. $125-128$

anonymous (2004b) "Wind of Change - Egypt says it wants to reform, but how much?" Annual Business Economic and Political Review: Egypt: available: www.oxfordbusinessgroup.com [accessed 01.11.2004], , pp. $23-24$

Apel, K. -O. (1988) Diskurs und Verantwortung: das Problem des Übergangs zur postkonventionellen Moral, Suhrkamp, Frankfurt a. M.

Ashenden, S. (1999) "Questions of Criticism - Habermas and Foucault on Civil Society and Resistance," in Ashenden \& Owen (eds.), pp. 143 - 165

Ashenden, S. \& Owen, D. (eds.) (1999) Foucault contra Habermas: Recasting the Dialogue between Genealogy and Critical Theory. SAGE, London

Brooke, C. (2002a) "What Does it Mean to be 'Critical' in IS Research?" Journal of Information Technology 17 , pp. $49-57$

Brooke, C. (2002b) "Critical Perspectives on Information Systems: An Impression of the Research Landscape," Journal of Information Technology 17, pp. 271 - 283

Burrell, G. (1994) "Modernism, Postmodernism and Organizational Analysis 4: The Contribution of Jürgen Habermas," Organization Studies (15:1), pp. 1 - 19

Burrell, G. \& Dale, K. (2003) "Building Better Worlds?: Architecture and Critical Management Studies," in Studying Management Critically, M. Alvesson \& H. Willmott (eds.) SAGE, London, pp. 177 - 196

Calás, M. B. \& Smircich, L. (1999) "Past Postmodernism? Reflections and Tentative Directions," Academy of Management Review (24:4), 1999, pp. 649 - 671

Cecez-Kecmanovic, D. (2001a) "Doing Critical IS Research: The Question of Methodology," in Qualitative Research in IS: Issues and Trends, E. Trauth (ed.), Idea Group Publishing, Hershey, pp. 141 - 162

Cecez-Kecmanovic, D. (2001b) "Critical Information Systems Research: A Habermasian Approach," Proceedings of the 9th European Conference on Information Systems, Bled, Slovenia, June 27-29, pp $253-263$

Cecez-Kecmanovic, D.; Janson, M. \& Brown, A. (2002) "The Rationality Framework for a Critical Study of Information Systems", Journal of Information Technology 17, pp. 215 - 227

Chan, A. (2000) "Redirecting Critique in Postmodern Organization Studies: The Perspective of Foucault," Organization Studies (21:6), pp. 1059 - 1075

Chua, W. F. (1986) "Radical Developments in Accounting Thought," The Accounting Review (61:4), pp. 601 $-632$

Chouliaraki, L. \& Fairclough, N. (1999) Discourse in Late Modernity - Rethinking Critical Discourse Analysis. Edinburgh University Press, Edinburgh

Ciborra, C. (2000)"A Critical Review of the Literature on the Management of Corporate Information Infrastructure" in From Control to Drift: The Dynamics of Corporate Information Infrastructures C. Ciborra, Claudio and Associates, Oxford University Press, Oxford, pp. 15 - 40

Coombs, R.; Knights, D. \& Willmott, H. C. (1992) "Culture, Control and Competition: Towards a Conceptual Framework for the Study of Information Technology in Organizations," Organization Studies (13:1), 1992, pp. $51-71$

Cooper, R. \& Burrell, G. (1988) "Modernism, Postmodernism and Organizational Analysis: An Introduction," Organization Studies (9:1), pp. 91 - 112

Cukier, W.; Middleton, C. \& Bauer, R. "The Discourse of Learning Technology in Canada: Understanding Communication Distortions and the Implications for Decision Making," in: Wynn et al. (2003), pp. $197-221$

Cukier, W.; Bauer, R. \& Middleton, C. "Applying Habermas' Validity Claims as a Standard for Critical Discourse Analysis," in: Kaplan et al. (2004), pp. 233 - 258 
Dawson, R. J. \& Newman, I. A. (2002) "Empowerment in IT Education," Journal of Information Technology Education (1:2), pp. 125 - 141

Deetz, S., (1992) "Disciplinary Power in the Modern Corporation," in Critical Management Studies, M. Alvesson \& Willmott, H. (eds.), SAGE, London, pp. 21 - 45

Doolin, B. (1998) "Information Technology as Disciplinary Technology: Being Critical in Interpretive Research on Information Systems," Journal of Information Technology 13 (Special Issue on Interpretive Research in Information Systems, edited by M. Myers and G. Walsham), pp. 301 - 311

Doolin, B. (2004) "Power and Resistance in the Implementation of a Medical Management Information System," Information Systems Journal (14), pp. 343 - 362

Edenius, M. (2003) "Discourse on E-Mail in Use," in Wynn et al. (2004), pp.73 - 90

Egypt (2004?) "Political System" available: http://www.presidency.gov.eg/html/political_system.html [accessed: 16. November 2004]

El Beltagi, I., McBride, N. \& Hardaker, G. (2005) " Evaluating the factors affecting DSS Usage by senior managers in local authorities in Egypt," Journal of Global Information Management (13:2), pp.42 - 65

El Sayed, H. \& Westrup, C. (2003) "Egypt and ICTs - How ICTs Bring National Initiatives, Global Organizations and Local Companies Together," Information Technology \& People (16:1), pp. 76 - 92

El Sherif, H. \& El Sawy, O. A. (1988) "Issue-Based Decision Support Systems for the Egyptian Cabinet," MIS Quarterly (12:4), pp. 551 - 569

Elkjaer, B.; Flensburg, P.; Mouritsen, J. \& Willmott, H (1991) "The Commodification of Expertise: The Case of Systems Development Consulting," Accounting, Management and Information Technologies (1)2, pp. $139-156$

Escobar, A. (1995) Development, Princeton University Press, Princeton, NJ.

Ess, C. (1996) "Introduction: Thoughts along the I-way: Philosophy and the emergence of computer-mediated communication," in Philosophical Perspectives on Computer-Mediated Communication, Ess, C. (ed.), State University of New York Press, Albany, pp. 1 - 12

Fairclough, N. (1995) Critical Discourse Analysis - The Critical Study of Language. Longman, London

Fairclough, N. (1993) "Critical Discourse Analysis and the Marketization of Public Discourse: The Universities," Discourse \& Society (4:2), pp. 133 - 168

Forester, J. (1992) "Critical Ethnography: On Fieldwork in a Habermasian Way," in: Critical Management Studies, M. Alvesson \& H. Willmott (eds.), SAGE, London, pp. 46 - 65

Foucault, M. (1980) "Powers and Strategies," in: Power/Knowledge - Selected Interviews and Other Writings (ed. C. Gordon), M. Foucault, The Harvester Press, Brighton, 1980, 134 - 145

Foucault, M. (1976) Histoire de la sexualité I: La volonté de savoir, Gallimard, Paris

Foucault, M. (1975) Surveiller et punir: Naissance de la prison, Gallimard, Paris

Foucault, M. (1971) L'ordre du discours, Gallimard, Paris

Grint, K. \& Woolgar, S. (1997) The Machine at Work: Technology, Work, and Organization, Blackwell, Cambridge

Habermas, J. (1996) Die Einbeziehung des Anderen - Studien zur politischen Theorie, Suhrkamp, Frankfurt a. M.

Habermas, J. 91994) "The Critique of Reason as an Unmasking of the Human Sciences: Michel Foucault," in Critique and Power: Recasting the Foucault / Habermas Debate, Kelly, M. (ed.), MIT Press, Cambridge, Massachusetts / London, pp. 47 - 78

Habermas, J. (1981a) Theorie des kommunikativen Handelns - Band I, Suhrkamp Verlag, Frankfurt a. M

Habermas, J. (1982b) Theorie des kommunikativen Handelns - Band II, Suhrkamp Verlag, Frankfurt a. M., $1981 b$

Heng, M. S. H. \& de Moor, A. (2003) "From Habermas's Communicative Theory to Practice on the Internet," Information Systems Journal (13), pp. 331 - 352

Hirschheim, R. \& Klein, H. K. (2003) "Crisis in the IS Field? A Critical Reflection on the State of the Discipline," Journal of the Association for Information Systems (4:5), pp. 237 - 293

Hirschheim, R. \& Klein, H. K (1994). "Realizing Emancipatory Principles in Information Systems Development: The Case for ETHICS," MIS Quarterly (18:1), pp. 83 - 109

Hirschheim, R. and Klein, H. K. (1989) "Four Paradigms of Information Systems Development," Communications of the ACM (32:10), pp. 1199 - 1216

Howcroft, D. \& Trauth, E. M. (2004) 'The Choice of Critical Information Systems Research,' in: Kaplan et al. (eds) (2004), pp. 196 - 211 
Howcroft, D. \& Wilson, M. (2003) "Paradoxes of participatory practices: the Janus role of the systems developer," Information and Organization (13:1), pp. 1 - 24

Introna, L. (2003) "Disciplining Information Systems: Truth and its Regimes," European Journal of Information Systems 12, pp. 235 - 240

Introna, L. \& Whittaker, L. (2004) "Truth, Journals, and Politics: The Case of the MIS Quarterly" in: Kaplan, et al. (eds.) (2004), pp. 103 - 120

ISDO, Information Society Development Office (2005?) "Mission Statement", available: http://www.isdo.gov.eg/mission.asp [accessed, 16.03.2005]

Jermier, J. M. \& Forbes, L. C (2003). "Greening Organizations: Critical Issues," in Studying Management Critically, M. Alvesson \& H. Willmott (eds.), SAGE, London, pp. 157 - 176

Kaplan, B.; Truex, D.; Wood-Harper, T.\& J. DeGross (eds.) (2004) Information Systems Research - Relevant Theory and Informed Practice. Kluwer Academic Publishers, Dordrecht, 2004

Kelly, M. (ed.) (1994) Critique and Power: Recasting the Foucault / Habermas Debate, MIT Press, Cambridge, Massachusetts / London

Klein, H. K. \& Huynh, M. Q, (2004) "The Critical Social Theory of Jürgen Habermas and its Implications for IS Research," In: Social Theory and Philosophy for Information Systems, Mingers, J. \& Willcocks, L. (eds.), Chichester: Wiley, pp. 157 - 237

Klein, H. K. \& Myers, M. D. (1999) "A Set of Principles for Conducting and Evaluating Interpretive Field Studies in Information Systems," MIS Quarterly (23:1), pp. 67 - 94

Klenow, P.J. \& Rodríguez -Clare, A. (1997) "Economic Growth: a review essay," Journal of Monetary Economics 40, pp. 597-617.

Knights, D. \& Morgan, G. (1991) "Corporate Strategy, Organizations, and Subjectivity: A Critique," Organization Studies (12:2), pp. 251 - 273

Knights, D. \& Willmott, H. (1991) Management Lives: Power and Identity in Organizations, Sage, London

Kvasny, L.; Greenhill, A. \& Trauth, E (2005) "Giving Voice to Feminist Projects in MIS Research," International Journal of Technology and Human Interaction (1:1), 2005, pp. 1 - 18

Kvasny, L. \& Trauth, E. (2003) "The Digital Divide at Work and Home: The Discourse about Power and Underrepresented Groups in the Information Society," in Wynn et al. (eds.) (2003), pp. 273 - 291

Levy, D. L.; Alvesson, M. \& Willmitt, H. (2003) "Critical Approaches to Strategic Management," in Studying Management Critically, M. Alvesson, Mats \& H. Willmott (eds.) SAGE, London, pp. 92 - 110

Lyytinen, K. (1992) "Information Systems and Critical Theory," in Critical Management Studies, M. Alvesson \& H. Willmott (eds.) SAGE, London, pp. 159 - 180

Lyytinen, K. \& Hirschheim, R. (1988) "Information Systems as Rational Discourse: an Application of Habermas Theory of Communicative Action," Scandinavian Journal of Management (4:1/2), pp. 19 30

Mansell, W.; Meteyard, B. \& Thomson, A. (1999) A Critical Introduction to Law, 2nd edition, Cavendish Publishing, London

Marx, K. (1969) Manifest der Kommunistischen Partei, Reclam, Stuttgart

McAulay, L.; Doherty, N. \& Keval, N. (2002) "The Stakeholder Dimension in Information Systems Evaluation," Journal of Information Technology 17, pp. 241 - 255

McGrath, K. (2005) "Doing Critical Research in Information Systems: A Case of Theory and Practice not Informing Each Other," Information Systems Journal (15), pp. 85 - 101

Mejias, R.J., Palmer, J.W. \& Harvey, M.G.(1999) "Emerging technologies, IT infrastructure, and economic development in Mexico", Journal of Global Information Technology Management (2:1), pp. 31-54.

Mingers, J. (1992) "Technical, Practical and Critical OR - Past, Present and Future?" in Critical Management Studies, M. Alvesson \& H. Willmott (eds.), SAGE, London, pp. 90 - 113

Montealegre, R. (1998) "Waves of change in adopting the Internet: lessons from four Latin American countries," Information Technology \& People (11:3), pp. 235-260.

Mubarak, H. (1999) "Address by President Muhammad Hosni Mubarak to The National Conference on The Promotion of Technology and Information" available: http://www.presidency.gov.eg/html/13_9.htm (accessed 16.11.2004), 13 Sep. 1999

Mubarak, H (2000) "President Mubarak's speech at the lunch hosted in his honor by Virginia's Governor" available: http://www.presidency.gov.eg/html/27-Mar2000_speech.htm (accessed 21.12.2004), 27 March 2000 
Ngwenyama, O. K. \& Lee, A. S. (1997) "Communication Richness in Electronic Mail: Critical Social Theory and the Contextuality of Meaning," MIS Quarterly (21:2), 1997, pp. 145 - 167

Nidumolu, S. R.; Goodman, S. E.; Vogel, D. R. \& Danowitz, A. K. (1996) "Information Technology for Local Administration Support: The Governorates Project in Egypt," MIS Quarterly (20:2), pp. 197 224

Nord, W. R. \& Jermier, J. M. (1992) "Critical Social Science for Managers? Promising and Perverse Possibilities," in Critical Management Studies, M. Alvesson, \& H. Willmott (eds.), SAGE, London, pp $202-222$

Orlikowski, W. J. \& Baroudi, J. J. (1991) "Studying Information Technology in Organizations: Research Approaches and Assumptions.," Information Systems Research (2:1), pp. 1 - 28

Probert, S. K. (2002) "Ethics, Authenticity and Emancipation in Information Systems Development," in: Ethical Issues of Information Systems, A. Salehnia (ed.), IRM Press, Hershey, pp. 249 - 254

Sahay, S. (2004) "Beyond Utopian and Nostalgic Views of Information Technology and Education: Implications for Research and Practice," Journal of the Association for Information Systems (5:7), pp. $282-313$

Saravanamuthu, K. (2002) "Information Technology and Ideology," Journal of Information Technology 17, 2002, pp. $79-87$

Schultze, U. \& Leidner, D. (2002) "Studying Knowledge Management in Information Systems Research: Discourses and Theoretical Assumptions," MIS Quarterly (26:3), pp. 213 - 242

Settle, A. \& Berthiaume, A. (2002) "Debating E-commerce: Engaging Students in Current Events," Journal of Information Systems Education 13(4), pp. 279 - 285

Shoib, G. M \& Jones, M. R. "Focusing on the Invisible: the Representation of IS in Egypt," Information Technology \& People (16:4), 2003, pp. 440 - 460

Stahl, B. C. (2008a): Information Systems: Critical Perspectives. Routledge, London

Stahl, B. C. (2008): "The Ethical Nature of Critical Research in Information Systems" In: Information Systems Journal (18:2), Special Issue on Exploring the Critical Agenda in IS Research, edited by Carole Brooke, Dubravka Cecez-Kecmanovic, Heinz K. Klein, 137 - 163

Stahl, B. C. (2006): "Emancipation in Cross-Cultural IS Research: The Fine Line between Relativism and Dictatorship of the Intellectual" Ethics and Information Technology (8:3), 97 - 108

Stahl, B. C. (2005) "The Paradigm of E-Commerce in E-Government and E-Democracy," in: Electronic Government Strategies and Implementation, Huang, Wayne; Siau, Keng \& Wei, Kwok Kee (eds), Idea Group Publishing, Hershey PA, pp. 1 - 19

Stahl, B. C. (2004a) "E-Teaching - the Economic Threat to the Ethical Legitimacy of Education?" Journal of Information Systems Education (15:2), 2004a, pp. 155 - 162

Stahl, B.C. \& El Beltagi, I., 2004b "Cultural Universality versus Particularity in CMC," Journal of Global Information Technology Management (7:4), pp. 47 - 65

Steffy, B. D. \& Grimes, A. J.(1992) "Personnel / Organization Psychology: A Critique of the Discipline," in Critical Management Studies, M. Alvesson \& H. Willmott, (eds.) SAGE, London, pp. 181 - 201

Temple, J. (1998) The New Growth Evidence, Institute of Economics and Statistics, Oxford

Ulrich, W. (2001) "A Philosophical Staircase for Information Systems Definition, Design, and Development," Journal of Information Technology Theory and Application (3:3), 2001, pp. 55 - 84

Varey, R. J.; Wood-Harper, T. \& Wood, B. (2002) "A Theoretical Review of Management and Information Systems Using a Critical Communications Theory," Journal of Information Technology 17, 2002, pp. $229-239$

Walsham, G. (2005) "Learning about Being Critical," Information Systems Journal (15), pp. 111 - 117

Walsham, G. (2001) Making a World of Difference - IT in a Global Context. Wiley, Chichester

Waring, T. (2004) "From Critical Theory into Information Systems Practice: A Case Study of a PayrollPersonnel System," in: Kaplan et al. (2004), pp. 556 - 575

Warschauer, M. (2003) "Dissecting the "Digital Divide": A Case Study in Egypt," The Information Society 19 , pp. $297-304$

Wastell, D. G. "Organizational Discourse as a Social Defense: Taming the Tiger of Electronic Government," in Global and Organizational Discourse About Information Technology, E. Wynn, E. Whitley, M. Myers, \& J. DeGross (eds.), Kluwer Academic Publishers, Dordrecht, 2003, pp. 179 - 195

Weizenbaum, J. (1976) Computer Power and Human Reason, W. H. Freeman and Company, San Francisco 
Willcocks, L. (2004) "Foucault, Power/Knowledge and Information Systems: Reconstructing the Present," in: Social Theory and Philosophy for Information Systems, J. Mingers \& L. Willcocks (eds.), Chichester: Wiley, pp. 238 - 296

Wilson, M. \& Howcraft, D. (2002) "Re-Conceptualising Failure: social Shaping Meets IS Research," European Journal of Information Systems 11, pp. 236 - 250

Wynn, E.; Whitley, E.; Myers, M. \& J. DeGross (eds.) (2003) Global and Organizational Discourse About Information Technology, Kluwer Academic Publishers, Dordrecht, 2003 